\title{
Use of Pyrolysis Oil from Scrap Tires with Control Module Adjustment of Diesel Engine
}

\author{
Jai-Houng Leu, ${ }^{1}$ Ming-Wei Shao, ${ }^{2}$ Tian-Syung Lan, ${ }^{3}$ \\ Xuan Sun, ${ }^{3 *}$ and Chih-Ying Chuang ${ }^{4}$ \\ ${ }^{1}$ Shandong Polytechnic, No. 23000, Jin Ten East Road, Jinan City, Shandong Province 250353, China \\ ${ }^{2}$ Department of Electrical Engineering, Dayeh University, Changhua 51591, Taiwan \\ ${ }^{3}$ College of Mechanical and Control Engineering, Guilin University of Technology, Guilin, Guangxi 541004, China \\ ${ }^{4}$ School of Electronic Information and Electrical Engineering, Huizhou University, \\ 46 Yanda Road, Huizhou, Guangdong 516007, China \\ (Received July 20, 2020; accepted December 4, 2020)
}

Keywords: electromechanical sensor, combustion efficiency, pollution emissions

Recycling oil from scrap rubber products, especially scrap tires, has contributed to reducing the use of fossil fuels. However, the impurities in recycled oil and the large emission of pollutants from the oil are problems yet to be solved. Therefore, the efficient use of pyrolysis oil (PO) from scrap tires needs investigation. We investigated the combustion efficiency, pollutant emission, and physicochemical properties of three different types of diesel (PO, 0\# diesel CNPC, B100) and two mixtures (PO with 0\# diesel CNPC and PO with B100) by testing and measurement. The mixtures had better properties, higher efficiency, and lower emission of pollutants (CO, HC, NOx, particulate matter) from an engine than each type of diesel. Similar output power was obtained for both tested fuel mixtures in this study. To obtain similar performances to 0\# diesel CNPC and PO with B100, it was necessary to adjust the engine control module (ECM). The results of this study provide information on how to use recycled fuels effectively with refined diesel, which suggests a way to reduce the use of fossil fuels and the emission of pollutants.

\section{Introduction}

There are differences between the combustion characteristics of recycled fuels and standard petrochemical diesel in a diesel engine. Thus, adjusting the engine control module (ECM) through measurement by sensors of the diesel engine is necessary to make the combustion characteristics of recycled fuels close to those of standard diesel.

Recycled fuels have become an important research topic as a means of energy saving and environmental protection. Scrap rubber products, especially scrap tires, are regarded as a good resource for extracting (recycling) diesel oil by pyrolysis. However, the impurities in pyrolysis oil (PO) and its low flash point result in unstable combustion, which may corrode the walls of the combustion rooms of engines. ${ }^{(1)}$ 
PO from scrap tires has been investigated in terms of production and combustion. İlkıliç and Aydın produced cracked oil from scrap tires at $350{ }^{\circ} \mathrm{C}$ and used the oil in mixtures with commercial diesel (D100). ${ }^{(2)}$ The mixtures contained the cracked oil and D100 in two different ratios (T10 and T20 bio-diesel). They adjusted the fuel injection volume and angle for effective engine operation using the mixtures on the basis of test data from a dynamometer. Changing the fuel injection angle reduced the emission of NOx and HC and increased the output power of a diesel engine. Their results showed that a suitable composition of fuel and control of the operating conditions of a diesel engine increased operating efficiency and reduced pollution emission. Murugan et al. carried out similar research using super diesel (D100) and PO from scrap tires in a single-cylinder diesel engine. ${ }^{(3)}$ They examined how the fuel consumption and output power were affected by controlling the heat release efficiency of the engine. Their results showed that the mixture increased the output power but did not reduce the fuel consumption. These studies indicate that further research is necessary to precisely investigate oil blending and perform engine testing under various conditions.

Chen proposed an environment-friendly coagulation-flocculation method that prevented the discoloration and gelation of PO and effectively removed impurities such as insoluble oxides, gums, and additives. ${ }^{(4)}$ To improve performance and reduce pollutant emission when using PO, Shei proposed the addition of ethanol and gasoline ${ }^{(5)}$ as the effective combustion of PO in a diesel engine is required to increase the use of $\mathrm{PO} .{ }^{(6)}$ Combusting $\mathrm{PO}$ alone and $\mathrm{PO}$ in a mixture with other fuels requires sophisticated control. ${ }^{(5)}$ The suitable timing and angle of fuel injection were proved to improve the output power and reduce the emission of nitrogen oxides (NOx) and hydrocarbons (HC) from a diesel engine. ${ }^{(4)}$

The ECM plays a critical role in controlling the combustion as it monitors the sensors of an engine, controls the timing of valves and ignition, and regulates the emission of exhaust gas. The ECM collects and processes the data from a mass airflow sensor, an oxygen sensor, an air-fuel sensor, and other sensors to control the combustion. To use PO as a fuel, the original parameters of the ECM need to be adjusted through various tests. Differences between the composition and properties of recycled fuels and diesel necessitate appropriate parameter measurements from the sensors of the ECM and their adjustment. This requires sophisticated sensing technology, and various tests are needed for the efficient use of PO. However, there has been no research on setting the ECM parameters to test the use of PO in an engine. Moreover, no comparison of the combustion and emission properties has been reported for PO and different types of diesel. Therefore, in this study, we evaluated the combustion and emission properties of PO, diesel, biodiesel, and their mixtures while adjusting the ECM. Suitable adjustment of the ECM is expected to lead to the widespread and efficient use of recycled fuels. The results of this study are expected to increase the feasibility and use of recycled fuels and contribute to the future development of environmental protection technology through the use of new materials.

\section{Methods}

Three different types of diesel were used in our experiment: PO produced by China Scrap Tire Gasification and Pyrolysis Plant, diesel (0\# diesel CNPC) from China National Petroleum 
Corporation, and biodiesel (B100) manufactured from rapeseed oil by Yuansheng Company, China. The following types of diesel and mixtures were tested to determine their combustion and emission characteristics: PO, 0\# diesel CNPC, B100, a mixture of PO and 0\# diesel CNPC (50:50 volume), and a mixture of recycled diesel and B100 (50:50 volume). The flash point, water content, sulfur content, heating value, kinematic viscosity, density, cetane number, carbon residue, and ash content of the fuels were measured in accordance with the test methods of the American Society for Testing and Materials. The physicochemical properties and pollutant emission of the different fuels were measured by an emission monitoring instrument approved by the Chinese government.

The specifications of the engine used in the tests are given in Table 1. To adjust the settings of the ECM, data were collected and analyzed from the crankshaft position sensor, camshaft position sensor, airflow sensor, restrictor sensor, knock sensor, and cooling-water temperature sensor. The data included engine speed, air input, coolant temperature, restrictor position, restrictor idle position, and engine knocking. Then, the ECM was adjusted to control the oil nozzle, heating plug, cooling fan, mechanical supercharging, injection timing, and sensor signal output (Fig. 1).

Table 1

Specifications of diesel engine used in tests.

\begin{tabular}{lc}
\hline Item & Specification \\
\hline Model & TOYOTA MK35SA \\
Displacement & 4.9 liter \\
Mileage & $270743 \mathrm{~km}$ \\
Engine type & Straight six-engine \\
Year of production & 1992 \\
Maximum power & $182.7 \mathrm{~kW}$ at $2600 \mathrm{RPM}$ \\
Total weight & $15000 \mathrm{~kg}$ \\
\hline
\end{tabular}

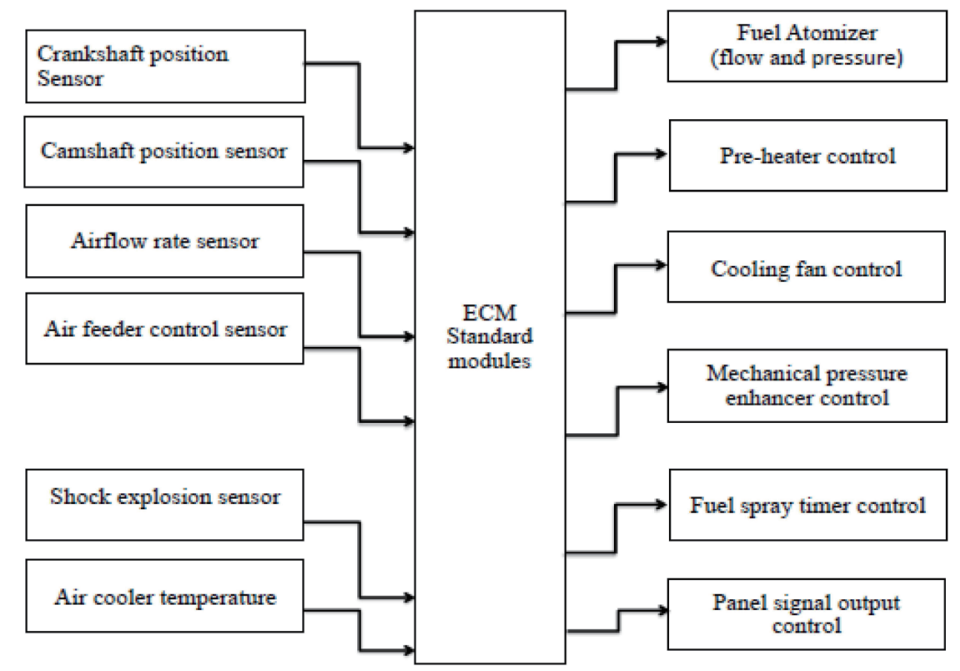

Fig. 1. ECM modulation mechanism. 


\section{Results and Discussion}

\subsection{Properties of diesels and mixtures}

PO showed a lower flash point, viscosity, and cetane number but a higher water content, sulfur content, density, carbon residue, and heating value than 0\# diesel CNPC and B100. In particular, the heating value of PO $(12103 \mathrm{kcal} / \mathrm{kg})$ was 9.3 and $24.2 \%$ higher than those of $0 \#$ diesel CNPC and B100, respectively. This property of PO suggests that it is an appropriate fuel for the diesel engine. However, its higher water and sulfur contents and larger amount of carbon residue caused more emission of NOx and HC than the other types of diesel and mixtures (Table 2). Thus, the emission of a diesel engine can be reduced while maintaining its output by using PO as an alternative fuel.

To examine the possibility of using PO with other types of diesel, we tested mixtures of PO with 0\# diesel CNPC and B100 in a volume ratio of 50:50. The mixtures had a higher heating value and cetane number but a lower sulfur content than PO. However, they contained more carbon residue and ash, and had a higher viscosity than 0\# diesel CNPC and B100.

\subsection{Settings of ECM}

Original settings of ECM

The diesel engine used in this study operated at $80 \%$ of the full torque at 1000 RPM. Thus, the torque output was $64 \%$ at the idle speed of 800 RPM. The original ECM preset a normal rotation speed of $1400 \mathrm{RPM}$. The output power of the engine was set to reach $90 \%$ of the maximum power at $2500 \mathrm{RPM}$, and the maximum power was reached at $3500 \mathrm{RPM}$. Without

Table 2

Physicochemical properties of different types of diesel in this study.

\begin{tabular}{|c|c|c|c|c|c|c|c|}
\hline Property & Unit & Test method & PO & $\begin{array}{l}\text { 0\# diesel } \\
\text { CNPC }\end{array}$ & B100 & $\begin{array}{c}\text { Recycled diesel + } \\
\text { 0\# diesel CNPC }\end{array}$ & $\begin{array}{c}\text { Recycled } \\
\text { diesel + B100 }\end{array}$ \\
\hline Flash point & ${ }^{\circ} \mathrm{C}$ & $\begin{array}{l}\text { ASTM } \\
\text { D93 }\end{array}$ & 27 & 71 & 163 & 56 & 69 \\
\hline Water content & $\mathrm{mg} / \mathrm{kg}$ & $\begin{array}{c}\text { ASTM } \\
\text { D95 } \\
\end{array}$ & 1.384 & 0.377 & 0.000 & 0.357 & 0.284 \\
\hline Sulfur content & $\%$ & $\begin{array}{l}\text { ASTM } \\
\text { D2622 }\end{array}$ & 1.15 & 0.17 & 0.00 & 0.36 & 0.05 \\
\hline Heating value & $\mathrm{kcal} / \mathrm{kg}$ & $\begin{array}{l}\text { ASTM } \\
\text { D240 }\end{array}$ & 11567 & 10578 & 9316 & 12013 & 10285 \\
\hline $\begin{array}{l}\text { Kinematic } \\
\text { viscosity }\end{array}$ & $\begin{array}{c}\text { At } 40^{\circ} \mathrm{C} \\
\mathrm{cST}\end{array}$ & $\begin{array}{c}\text { ASTM } \\
\text { D445 }\end{array}$ & 1.83 & 3.29 & 4.56 & 4.05 & 3.48 \\
\hline Density & $\mathrm{g} / \mathrm{cm}^{3}$ & $\begin{array}{l}\text { ASTM } \\
\text { D1298 }\end{array}$ & 0.94 & 0.87 & 0.94 & 0.88 & 0.83 \\
\hline Cetane number & & $\begin{array}{c}\text { ASTM } \\
\text { D976 } \\
\end{array}$ & 34.02 & 51.35 & 50.91 & 41.29 & 46.55 \\
\hline Carbon residue & $\mathrm{g} / \mathrm{kg}$ & $\begin{array}{l}\text { ASTM } \\
\text { D254 }\end{array}$ & 0.846 & 0.199 & 0.038 & 0.461 & 0.254 \\
\hline Ash content & $\mathrm{g} / \mathrm{kg}$ & $\begin{array}{l}\text { ASTM } \\
\text { D482 }\end{array}$ & 0.18 & 0.01 & 0.03 & 0.06 & 0.02 \\
\hline
\end{tabular}


the adjustment, the rate of increase of the output power decreased above 1750 RPM. The stability of the engine with the original ECM settings was maintained as \pm 200 RPM. The ECM was originally set to flameout the engine at a certain temperature to prevent the engine from overheating, which was not appropriate when using the PO in this study as it had a high heating value of $11567 \mathrm{kcal} / \mathrm{kg}$. When the PO was used with the original ECM settings, the maximum power was reached at both 1600 and 2750 RPM. The premature ignition in the combustion process due to the solvent in the PO and the overheating of the engine block contributed to this phenomenon.

\section{Adjusted settings of ECM}

To use the PO and its mixtures effectively, the ECM in the engine was adjusted with a plugin correction system to give it a rotation speed in the range between 750 and 4500 RPM. As the PO caused premature ignition, which was most severe at $2500 \mathrm{RPM}$, a protective program was installed in the ECM that cut the fuel supply to avoid flameout. The ECM was adjusted to maintain $75 \%$ of the full power at 1500 RPM, so the engine power output was constant at 72 horsepower (HP). The output power with the adjusted ECM was 4 HP less than that with the original ECM at $75 \%$ of the full power. The maximum torque of $265 \mathrm{~N} \cdot \mathrm{m}$ occurred at $1400 \mathrm{RPM}$ with the adjusted ECM. The torque was lower than that with the original ECM, but the engine stability ( $\pm 25 \mathrm{RPM}$ ), the cooling-water temperature, and the emission were improved. The adjusted ECM had a stable operation with BTC21 (the crankshaft turns $21^{\circ}$ before injecting fuel into the combustion chamber after the crank of the reciprocating engine starts from the bottom of the piston), a fuel injection pressure of $90 \mathrm{~kg} / \mathrm{cm}^{2}$ at $1400 \mathrm{RPM}$, and an operating temperature of $83{ }^{\circ} \mathrm{C}$. Under the control of the ECM, signal feedback was received with a fuzzy logical operation.

\subsection{Emission of pollutants with adjusted ECM}

Table 3 shows the emission of pollutants from the three types of diesel and two mixtures. PO had the highest concentrations of $\mathrm{CO}, \mathrm{NOx}$, particulate matter (PM), and smoke in the exhaust air but the lowest concentration of $\mathrm{HC}$ among the fuels. B100 had the lowest concentration of $\mathrm{CO}, \mathrm{HC}, \mathrm{PM}$, and smoke, which reflects the characteristics of biodiesel as a clean fuel. 0\# diesel CNPC had lower concentrations of PM and smoke than PO but higher concentrations than B100.

Table 3

Emission of pollutants from combustion of different fuels.

\begin{tabular}{lcccccc}
\hline Pollutant & Unit & PO & 0\# diesel CNPC & B100 & $\begin{array}{c}\text { Recycled diesel } \\
+ \text { 0\# diesel CNPC }\end{array}$ & $\begin{array}{c}\text { Recycled diesel } \\
+ \text { B100 }\end{array}$ \\
\hline CO & $\mathrm{g} / \mathrm{kw} \cdot \mathrm{h}$ & 5.97 & 2.15 & 1.83 & 1.72 & 1.43 \\
$\mathrm{HC}$ & $\mathrm{g} / \mathrm{kw} \cdot \mathrm{h}$ & 0.284 & 0.451 & 0.269 & 0.626 & 0.331 \\
$\mathrm{NOx}$ & $\mathrm{g} / \mathrm{kw} \cdot \mathrm{h}$ & 11.932 & 7.1162 & 8.218 & 10.220 & 9.361 \\
$\mathrm{PM}$ & $\mathrm{g} / \mathrm{kw} \cdot \mathrm{h}$ & 2.336 & 0.145 & 0.077 & 0.114 & 0.096 \\
Smoke & $\mathrm{g} / \mathrm{kg}$ & 69.3 & 54.6 & 31.9 & 41.3 & 38.9 \\
\hline
\end{tabular}


The emission from the mixture of PO with 0\# diesel CNPC had lower concentrations of $\mathrm{CO}, \mathrm{PM}$, and smoke than that from the other fuels. The concentrations of CO, PM, and smoke emitted by the mixture were 29,5 , and $60 \%$ of those emitted by PO, respectively. The emission from the mixture of PO with B100 contained the lowest concentrations of $\mathrm{CO}, \mathrm{HC}, \mathrm{PM}$, and smoke, which were $24,83,4$, and $56 \%$ of those from PO, respectively. The mixture of PO with 0\# diesel CNPC emitted the highest concentration of HC and NOx. B100 emitted the lowest concentrations of $\mathrm{HC}$ and $\mathrm{PM}$ as it contains no water or sulfur. In general, the mixtures of PO with B100 and PO with 0\# diesel CNPC were more environment-friendly. These results are closely related to the physicochemical properties of each fuel (Table 2).

\section{Conclusions}

The results of this study suggest that the mixtures of PO with B100 and PO with 0\# diesel CNPC are advantageous in reducing emission and enhancing output power. The efficiency of combustion was increased owing to the high heating value, which was mainly contributed to by long- and short-chain molecules bonded in the mixture. In addition, PO, B100, and biodiesel have complementary properties. The performance and emission of the mixtures were similar to those of B100 and their heating values were higher than that of 0\# diesel CNPC. The mixtures of PO with B100 and PO with 0\# diesel CNPC had higher cetane numbers than PO, 0\# diesel CNPC, and B100, resulting in improved combustion efficiency. The mixtures had higher residual carbon and ash contents than 0\# diesel CNPC and B100, which had no significant impact on the overall combustion efficiency. The sulfur contents of the mixtures were significantly less than those of PO and 0\# diesel CNPC. The mixtures emitted more HC and NOx but less CO, PM, and smoke. To reduce the emission of the pollutants, it is necessary to refine the mixtures to remove foreign matter and colloids. This will also enhance the power of the diesel engine. Upon increasing their quality, the mixtures can be used as lower-cost alternatives to diesel while retaining similar properties to 0\# diesel CNPC. The mixtures of PO with B100 and PO with 0\# diesel CNPC were found to be appropriate for a diesel engine upon the adjustment of the ECM through the use of advanced sensor and data processing technology.

\section{References}

1 M. W. Shao: Mater. Res. Innov. 19 (2015) 58. https://doi.org/10.1179/1432891715Z.0000000001819

2 C. İlkılıç and H. Aydın: Fuel Process. Technol. 92 (2011) 1129. https://doi.org/10.1016/j.fuproc.2011.01.009

3 S. Murugan, C. Ramaswamy, and G. Nagarajan: Waste Manage. 28 (2008) 2743. https://doi.org/10.1016/ j.wasman.2008.03.007

4 K. W. Chen: Adv. Mater. Res. 852 (2014) 768. https://doi.org/10.4028/www.scientific.net/amr.852.772

5 W. T. Shei: Combustion Characteristics, Pollution Analysis and Engine Test of Ethanol-gasoline Blended Fuel, Master's Thesis, National Cheng Kung University, Tainan, Taiwan (1999) p. 65.

6 G. Adi, C. Hall, B. Tao, and G. Shaver: 2012 IFAC Proc. (IFAC, 2012) 45 (2012) 17. https://doi. org/10.3182/20121023-3-FR-4025.00037 